Research Article

\title{
Genetic variation in the Solanaceae fruit bearing species lulo and tree tomato revealed by Conserved Ortholog (COSII) markers
}

\author{
Felix Enciso-Rodríguez ${ }^{1}$, Rodrigo Martínez ${ }^{1}$, Mario Lobo $^{2}$ and Luz Stella Barrero ${ }^{1}$ \\ ${ }^{1}$ Biotechnology and Bioindustry Center, Colombian Corporation for Agricultural Research, CORPOICA, \\ Mosquera, Cundinamarca, Colombia. \\ 2 "La Selva” Research Center, CORPOICA, Rionegro, Antioquia, Colombia.
}

\begin{abstract}
The Lulo or naranjilla (Solanum quitoense Lam.) and the tree tomato or tamarillo (Solanum betaceum Cav. Sendt.) are both Andean tropical fruit species with high nutritional value and the potential for becoming premium products in local and export markets. Herein, we present a report on the genetic characterization of 62 accessions of lulos ( $n=$ 32) and tree tomatoes $(n=30)$ through the use of PCR-based markers developed from single-copy conserved orthologous genes (COSII) in other Solanaceae (Asterid) species. We successfully PCR amplified a set of these markers for lulos (34 out of 46 initially tested) and tree tomatoes (26 out of 41 ) for molecular studies. Six polymorphic COSII markers were found in lulo with a total of 47 alleles and five polymorphic markers in tree tomato with a total of 39 alleles in the two populations. Further genetic analyses indicated a high population structure (with $F_{\text {ST }}>0.90$ ), which may be a result of low migration between populations, adaptation to various niches and the number of markers evaluated. We propose COSII markers as sound tools for molecular studies, conservation and the breeding of these two fruit species.
\end{abstract}

Key words: COSII, genetic diversity, lulo, tree tomato.

Received: February 2, 2009; Accepted: October 6, 2009.

\section{Introduction}

The Lulo or naranjilla (Solanum quitoense Lam.) and the tree tomato or tamarillo (Solanum betaceum Cav. Sendt.) are edible fruits belonging to the Solanaceae family. The primary center of diversity for lulo comprises the Andean region of Colombia, Ecuador and Peru (Whalen et al., 1981; Heiser and Anderson, 1999; Lobo et al., 2007), whereas that for the tree tomato, besides the aforementioned, also includes Bolivia (Bohs, 1994). These fruits are mainly planted in the Andean region, expanding there from to other parts of the world, lulos to the subtropics of Central America and tree tomatoes to New Zealand and various Asian and African countries. The fruit of both can be eaten either raw or cooked, besides being widely used for making juice, pies, jelly, jam, ice cream, as well as for medicinal purposes. In addition, they are noted for their nutritional value due to the high content of vitamins $\mathrm{A}$ and $\mathrm{C}$, minerals and carbohydrates (Heiser and Anderson, 1999; Agronet, 2009).

Send correspondence to Luz Stella Barrero. Biotechnology and Bioindustry Center, Colombian Corporation for Agricultural Research, CORPOICA, AA 240142 Las Palmas, kilómetro 14, vía Mosquera, Cundinamarca, Colombia. E-mail: lbarrero@ corpoica.org.co.
Based on a series of controlled crosses, phylogenetic relationships in lulos, tree tomatoes and related species have been established. $S$. quitoense can form fertile hybrids with $S$. hirtum, whereas in $S$. betaceum, this is possible with S. unilobum (Heiser, 1972; Bohs, 1991, 1994; Bernal et al., 1998 Lobo et al., 2000, 2007). These findings have been useful for generating improved material, thereby culminating in a cultivar known as "Lulo La Selva", a cross between $S$. quitoense and $S$. hirtum, which is now available to the public (Bernal et al., 1998). As regards tree tomatoes, no improved breeding material is publicly available. Nevertheless, as a result of breeding programs, various hybrids between $S$. betaceum and $S$. unilobum are being evaluated in Colombian fields (Lobo et al., 2000).

In order to further genetic improvement, the characterization of a broad genetic base is required. In accordance, the Colombian Corporation for Agricultural Research -CORPOICA- maintains 159 entries of lulos and related species from the Lasiocarpa section, and 75 tree tomatoes and related taxa from Ecuador, Peru, Bolivia, Brazil, Venezuela, Costa Rica, Trinidad and India, together with a large representation from Colombia itself. These collections have been partially characterized by using phenotypic information (Benitez et al., 1991; Lobo et al., 2007). Furthermore, the lulo collection has been additionally 
characterized through molecular AFLP markers (M. Lobo, unpublished results). Nevertheless, additional informative (co-dominant) markers are necessary for a precise assessment of genetic variation, for use in both conservation and breeding programs.

In 2004, a consortium of some 30 countries embarked on an International Solanaceae Genomics Project -SOL- , with the mission of developing genomics tools for this family (Mueller et al., 2005). One of the tools developed by SOL is the Conserved Ortholog Set (COS) markers, suitable for evolutionary, phylogenetic, and comparative genomic studies in Asterid species where the Solanaceae family is widely represented (Fulton et al., 2002). The comparison of tomato ESTs to pepper, potatoes, eggplants, coffee and the complete gene set from Arabidopsis, has resulted in a combined COS set composed of 2,869 unigenes across these species. This second generation of markers (COSII) includes Universal Primers for Asterid species (UPA) from COS genes designed to amplify intronic (iUPA) and/or exonic (eUPA) regions, thereby providing greater flexibility in the identification of polymorphisms (Wu et al., 2006). More recently, additional sets of COS genes have been generated for diversity studies in tomatoes (Van Deynze et al., 2007). Due to their conserved nature, COSII markers may be transferred among species of the Asterid clade through amplification of universal primers without the need for investing in sequencing costs, thus representing an economic alternative to other types of codominant markers such as SSRs, whose generation is usually costly and time-consuming, as prior sequencing steps are required for their development. We evaluated COSII markers in lulos and tree tomatoes in a sample from the CORPOICA collection, and successfully transferred markers for studies of genetic variation in these species. Here, we show how genomic information maintained by the SOL project in well-known species, such as tomatoes, can be used in species where little or no genomic information is available, such as lulos and tree tomatoes.

\section{Materials and Methods}

\section{Plant material and DNA isolation}

Thirty accessions of lulos, two entries of the related species S. hirtum, and 26 accessions of tree tomatoes, as well as four entries of the relative species $S$. corymbiflora, $S$. diversifolia and $S$. hartwegii (Table 1), with five seedlings per accession, were selected from the CORPOICA germplasm collection based on geographic distribution. Genomic DNA was isolated from young leaves of each seedling, following the procedure described by Fulton et al. (1995), by using approximately $2 \mathrm{~g}$ of leaves in $1 \mathrm{~mL}$ of extraction buffer, with the exception of the final concentration of sodium bisulfite, which was $1.6 \%(\mathrm{w} / \mathrm{v})$. The quantity and quality of genomic DNA were checked using a
Beckman $\mathrm{DU}^{\circledR} 530$ spectrophotometer and on $1 \%(\mathrm{w} / \mathrm{v})$ agarose gels.

\section{PCR amplification}

Forty six candidate COSII markers for lulos and 41 for tree tomatoes, were selected mainly in silico from more than 400 markers, based on the presence of Single Nucleotide Polymorphisms (SNPs) or Insertions/Deletions (InDels) in the lulos and tree tomatoes themselves (Table S1; Pratt et al., 2008). PCR amplification was carried out in an i-Cycler thermal Cycler (Bio-Rad, Hercules, CA, USA) as follows: one cycle of initial denaturation for $5 \mathrm{~min}$ at $94{ }^{\circ} \mathrm{C}$, followed by 35 cycles for $30 \mathrm{~s}$ at $94{ }^{\circ} \mathrm{C}, 1 \mathrm{~min}$ at $55^{\circ} \mathrm{C}$ and $2 \mathrm{~min}$ at $72{ }^{\circ} \mathrm{C}$, followed by a final extension of 10 min at $72{ }^{\circ} \mathrm{C}$, and preservation at $4{ }^{\circ} \mathrm{C}$ until further analysis. PCR conditions were optimized for $25 \mu \mathrm{L}$ of reaction mixture by using $0.1 \mu \mathrm{M}$ of each primer and $25 \mathrm{ng}$ of template DNA. Amplification products were separated by gel electrophoresis on $2 \%(\mathrm{w} / \mathrm{v})$ agarose in a $1 \mathrm{X}$ TAE buffer (40 mM Tris-acetate and $1 \mathrm{mM}$ EDTA), and then stained with ethidium bromide $(0.5 \mu \mathrm{g} / \mathrm{mL})$.

\section{Statistical analysis}

Stained PCR products were visualized with GeneSnap software for Windows XP, using the $1 \mathrm{~kb}$ plus DNA ladder as standard (Invitrogen, Carlsbad, CA, USA). Products showing different sizes $(\mathrm{pb})$ i.e. polymorphic by insertions/deletions (InDels $>20 \mathrm{pb}$ ) were considered different alleles of the same COSII locus. The number of alleles per COSII locus was counted, whereupon each allele was assigned a consecutive number. A matrix of alleles per locus vs. accessions was generated.

Ho (observed heterozygosity) and He (expected heterozygosity) were calculated as described by Hartl (1987). Population structure was estimated using Wright's F-statistics ( $\mathrm{F}_{\mathrm{IS}}$ : inbreeding coefficient, $\mathrm{F}_{\mathrm{IT}}$ : measure of the genetic differentiation over populations, $\mathrm{F}_{\mathrm{ST}}$ : variance of allele frequencies among populations) (Wright, 1965).

Principal component (PC), genetic diversity, and population structure analysis were performed using Genetix 4.05 (Belkhir et al., 2004). Genetic distances were calculated using the Cavalli-Sforza distance measure (Cavalli-Sforza and Edwards, 1967), as this distance-method is employed to analyze gene frequencies without complying to any biological assumption, and is especially useful in cases where little is known about the evolutionary forces driving genetic change. Dendograms were generated by way of the Unweighted Pair Group Method (UPGMA). Bootstrapping with 10,000 replicates was carried out to assess statistical support for each cluster. Consensus trees were constructed using PHYLIP 3.5 (Felsenstein, 1989). 
Table 1 - Accessions of lulos, tree tomatoes and the related taxa used in this study.

\begin{tabular}{|c|c|c|c|c|c|}
\hline Species & Accession & Origin $^{1}$ & Species & Accession & Origin $^{1}$ \\
\hline S. quitoense & $04 \mathrm{~T} 14203$ & Valle & S. betaceum & 06TA001 & Antioquia \\
\hline S. quitoense & 06L053 & Huila & S. betaceum & 06TA004 & Nariño \\
\hline S. quitoense & 06L054 & Peru* & S. betaceum & 06TA007 & Nariño \\
\hline S. quitoense & 06L061 & Antioquia & S. betaceum & 06TA008 & Cauca \\
\hline S. quitoense & 06L062 & Antioquia & S. betaceum & 06TA009 & Valle \\
\hline S. quitoense & 06L064 & Putumayo & S. betaceum & 06TA010 & Antioquia \\
\hline S. quitoense & 06L066 & Valle & S. betaceum & 06TA011 & Caldas \\
\hline S. quitoense & 06L068 & Nariño & S. betaceum & 06TA013 & Caldas \\
\hline S. quitoense & 06L069 & Valle & S. betaceum & 06TA014 & Boyaca \\
\hline S. quitoense & 06L070 & Cauca & S. betaceum & 06TA015 & Tolima \\
\hline S. quitoense & 06L071 & Cauca & S. betaceum & 06TA016 & Tolima \\
\hline S. quitoense & 06L072 & Valle & S. betaceum & 06TA018 & Antioquia \\
\hline S. quitoense & 06L074 & Cauca & S. betaceum & 06TA020 & Antioquia \\
\hline S. quitoense & 06L075 & Cauca & S. betaceum & 06TA022 & Unknown \\
\hline S. quitoense & 06L078 & Valle & S. betaceum & 06TA023 & Tolima \\
\hline S. quitoense & 06L080 & Valle & S. betaceum & 06TA024 & Antioquia \\
\hline S. quitoense & 06L081 & Valle & S. betaceum & 06TA025 & Narino \\
\hline S. quitoense & 06L082 & Valle & S. betaceum & 06TA026 & Huila \\
\hline S. quitoense & 06L084 & Unknown & S. betaceum & 06TA028 & Antioquia \\
\hline S. quitoense & 06L085 & Magdalena & S. betaceum & 06TA031 & Antioquia \\
\hline S. quitoense & 06L088 & Antioquia & S. betaceum & 06TA032 & Antioquia \\
\hline S. quitoense & 06L089 & Unknown & S. betaceum & 06TA033 & Antioquia \\
\hline S. quitoense & 06L090 & Antioquia & S. betaceum & 06TA034 & Nariño \\
\hline S. quitoense & 06L091 & Costa Rica* & S. betaceum & 06TA039 & Kenya* \\
\hline S. quitoense & 06L093 & Boyaca & S. betaceum & 06TA041 & Ecuador* \\
\hline S. quitoense & 06L094 & Antioquia & S. betaceum & 06TA047 & Caldas \\
\hline S. quitoense & 06L095 & Magdalena & S. corymbiflora ${ }^{2}$ & 06TA042 & Brazil* \\
\hline S. quitoense & 06L097 & Santander & S. diversifolia ${ }^{2}$ & 06TA050 & Unknown \\
\hline S. quitoense & 06L098 & Antioquia & S. diversifolia ${ }^{2}$ & 06TA045 & Venezuela* \\
\hline S. quitoense & 06L099 & Norte de Santander & S. hartwegii var. racemosa ${ }^{2}$ & 06TA035 & Tolima \\
\hline S. hirtum ${ }^{2}$ & $05 \mathrm{~T} 1688028$ & Venezuela* & & & \\
\hline S. hirtum ${ }^{2}$ & 06L063 & Santander & & & \\
\hline
\end{tabular}

${ }^{1}$ The region of original sampling is indicated for accessions from Colombia. ${ }^{2}$ Related taxa. Accessions from other countries are denoted by *. All accessions are conserved as seeds.

\section{Results and Discussion}

\section{Polymorphism}

Polymorphism assessed in lulos showed that among 46 COSII markers initially selected, 34 were successfully transferred and PCR amplified, six being polymorphic by InDel as observed by agarose gel electrophoresis. The polymorphic COSII markers were previously classified as iUPAs due to amplification of intronic regions and also mapped to four different tomato chromosomes (Mueller et al., 2005; Table 2). The six COSII markers tested on the panel of 32 accessions revealed a total of 47 alleles and an average of 7.8 alleles per locus. The locus C2_At4g37280 presented the highest number of alleles (15) and the locus C2_At4g38810 the lowest (four) (Table 2).

In tree tomatoes, among the 41 initially selected COSII markers, 26 were successfully transferred, five of these being polymorphic by InDel as observed by agarose gel electrophoresis. The polymorphic COSII markers were mapped to five different tomato chromosomes and classified as iUPAs, with the exception of locus C2_At3g15430, which was identified as eUPA, due to amplification of the exonic region (Mueller et al, 2005). The five COSII markers tested on a panel of 30 accessions revealed a total of 39 alleles and an average of 7.8 alleles per locus. The number 


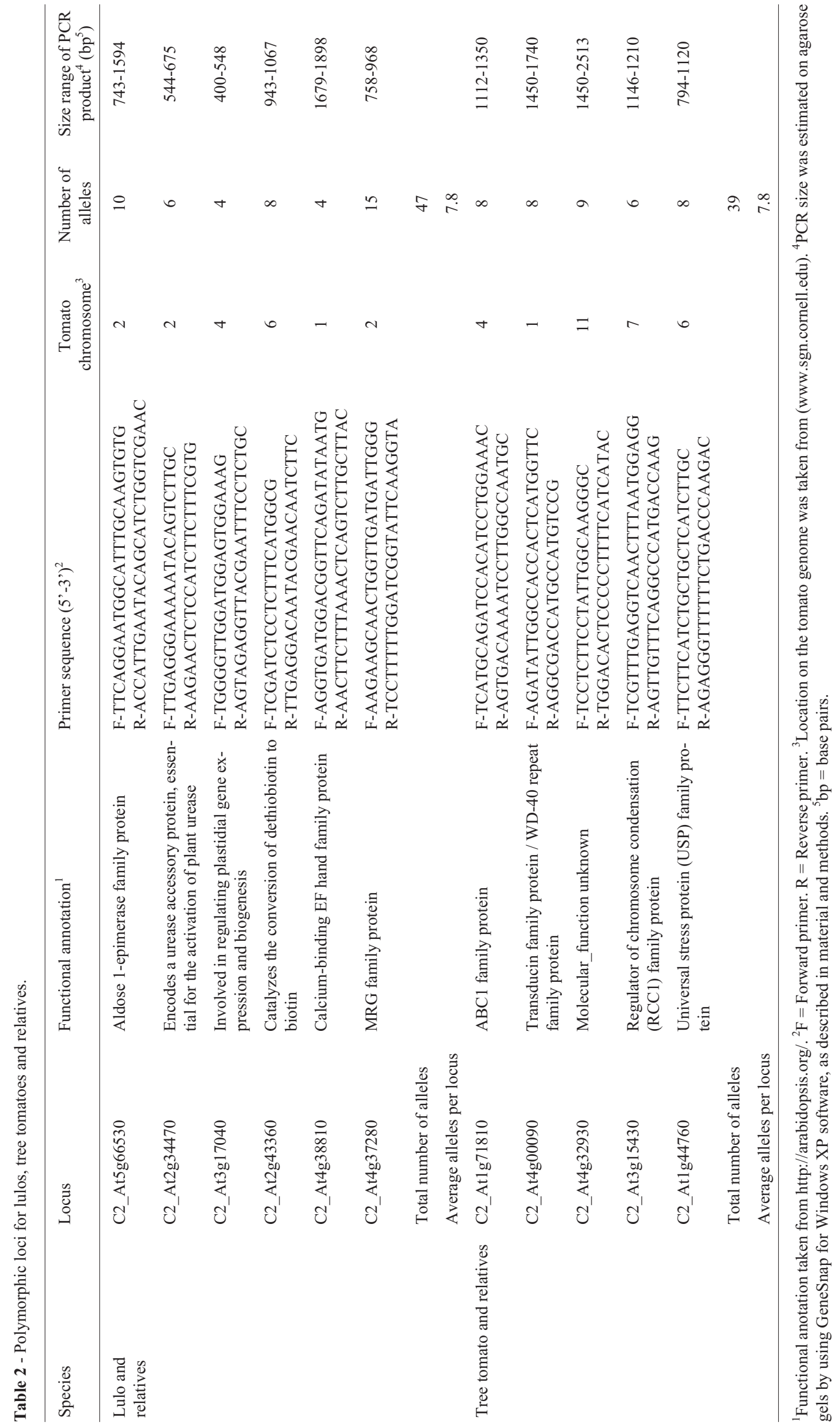


of alleles was the highest (9) in locus $\mathrm{C} 2 \_4 \mathrm{~g} 32930$, and the lowest (6) in C2_At3g15430 (Table 2).

To our knowledge, this is the first report describing the use of Asterid COSII polymorphisms for studies on diversity, based on the size of PCR products. However, it is possible that genetic diversity is thereby underestimated, due to the low resolution provided by $2 \%$ agarose gels, since differences in a few base pairs (less than 20) are not detected on analysis. Other reports are based on COS sequence information, probably more informative and reliable than that founded on PCR product size (Nakitandwe et al., 2007; Van Deynze et al., 2007). Nevertheless, the evaluation of InDels ( $>20$ base pairs) in agarose gels could provide valuable information and represent an economic alternative to direct Sanger DNA sequencing. Further studies of polymorphisms based on the estimation of PCR size on gel and the sequencing of PCR products by using the same COSII, are imperative for comparison.

We compared the results generated in this study based on PCR product size using COSII, with others employing microsatellites (SSRs) in Asterids. We found that the number of COSII polymorphic markers identified herein (5-6 polymorphic out of 26-34 initially tested, about $19 \%$ and $18 \%$, respectively, Table 2) were comparable to reports on results with SSRs, despite fundamental differences in the markers used to estimate genetic diversity, nevertheless, both markers are similar as regards the presence of multiple and null alleles, co-dominance and presence of InDels. For example, in potatoes, three SSR markers were polymorphic out of 27 initially tested (about $11 \%$, Bornet et al., 2002), and, 18 out of 156 were polymorphic in the same species (about 12\%, Ghislain et al., 2004). Likewise, the average number of alleles per locus was higher in the present study (7.8 per species) when compared to other SSR reports. For example, in diploid coffee, four alleles per locus were found (Moncada and McCouch, 2004), and in tomatoes, 2.7 (He et al., 2003). Since these comparisons are among different species, material and mating systems, care must be taken and the results only considered indicative of successful COSII rates. Further comparison with SSRs within the same entries and species evaluated is desirable.

\section{Genetic diversity and population structure}

Heterozygosity values per accession and locus were low, with $\mathrm{Ho}$ and He averages of 0.03 and 0.05 for lulos and 0.003 for tree tomatoes (Table 3 ). A preliminary population structure analysis, with the data assessed both per accession and locus, revealed extremely high values. Thus, $\mathrm{F}_{\mathrm{IS}}, \mathrm{F}_{\mathrm{IT}}$, and $\mathrm{F}_{\mathrm{ST}}$ averages per accession were $0.42,0.96,0.93$ for lulos, and $0.86,0.99,0.99$ for tree tomatoes, respectively. Averages per locus were $0.47,0.96,0.92$ for lulos, and $0.43,0.99,0.99$ for tree tomatoes, respectively (Table 3). The high $\mathrm{F}_{\mathrm{IS}}$ and $\mathrm{F}_{\mathrm{IT}}$ values are related to a deficit in heterozygotes within accessions (subpopulations) and are in accordance with the low Ho and He values per accession and locus (Table 3). Analysis revealed population structures in both lulos and tree tomatoes, with high homozygosis (fixation of alleles) within accessions and high mutual genetic differentiation, i.e. almost no sharing of alleles.

The high population structure and diversity may be explained by several factors including, in the first place, geographical distribution. Both lulos and tree tomatoes are natives of the Andean region, near the equator, comprising dramatically variable habitats, as rain forests, deserts and high mountains, with regular snowfall and sub-freezing temperatures. Thus the species were unperturbed by ice age conditions, and may have had time to accumulate adaptive genetic variation to extreme ecological niches (Heiser and Anderson, 1999; Bohs, 2004; Mueller et al., 2005; Lobo et al., 2007). In the present study, we used a different geographical sample representing several Colombian regions (Table 1), this including a wide range of habitats ideal for the establishment of different niches, possibly inapt for genetic flow among accessions. In the second place, sampling populations were obtained mainly from small orchards planted by local farmers with few individuals per location, and with the absence of or reduced migration between demes, thus probably giving rise to low sharing of alleles among accessions and genetic drift. The third point is the mating system. Although some studies have reported a high natural cross pollination rate, both lulos and tree tomatoes have also been described as self-compatible species (Heiser, 1972; Benítez et al., 1991; Bohs, 1994), thus adept

Table 3 - Heterozygosity and fixation indexes per locus and accession.

\begin{tabular}{llccccc}
\hline Species & \multicolumn{5}{c}{ Average and range of Indexes ${ }^{1}$} \\
\cline { 2 - 6 } & & $\mathrm{H}_{\mathrm{o}}{ }^{2}$ & $\mathrm{H}_{\mathrm{e}}{ }^{3}$ & $\mathrm{~F}_{\mathrm{IS}}{ }^{4}$ & $\mathrm{~F}_{\mathrm{IT}}{ }^{5}$ & $\mathrm{~F}_{\mathrm{ST}}{ }^{6}$ \\
\hline Lulo and relatives & Accession & $0.03(0-0.23)$ & $0.05(0-0.29)$ & $0.42(0.4-0.6)$ & $0.96(0.95-0.97)$ & $0.93(0.92-0.94)$ \\
& Locus & $0.03(0-0.09)$ & $0.05(0-0.14)$ & $0.47(0.41-0.50)$ & $0.96(0.95-0.97)$ & $0.92(0.9-0.95)$ \\
\multirow{2}{*}{ Tree tomato and relatives } & Accession & $0.003(0-0.08)$ & $0.003(0-0.1)$ & $0.86(0.86-1)$ & $0.99(0.99-1)$ & $0.99(0.99-1)$ \\
& Locus & $0.003(0-0.01)$ & $0.003(0-0.02)$ & $0.43(0.28-1)$ & $0.99(0.99-1)$ & $0.99(0.99-1)$ \\
\hline
\end{tabular}

${ }^{1}$ Range is indicated in parenthesis, ${ }^{2}$ Observed heterozygosity, ${ }^{3}$ Expected heterozygosity, ${ }^{4}$ Inbreeding coefficient, ${ }^{5}$ Measure of genetic differentiation over populations, ${ }^{6}$ Variance of allele frequencies among populations. 
to self-fertilization, propitious for the fixation of alleles. Finally, the type of markers, as the only type of COSII polymorphism analyzed in this study were insertions / deletions (InDels $>20$ base pairs), apparent in the different sizes of PCR products. We could also consider as another type of polymorphism, the presence of null alleles, which may contribute to the shortage of heterozygotes observed within populations, a phenomenon also reported for SSRs (Varshney et al., 2005).

\section{Principal component and cluster analysis}

PC analysis revealed four factors (axes) explaining $36.82 \%$ of the total genetic variation in lulos and $35.27 \%$ in tree tomatoes, each factor contributing a similar percentage of variance $(8.04-10.57 \%$ for lulos and $7.65-10.69 \%$ for tree tomatoes). The distribution of populations in the three dimensions revealed by the first three PCs showed defined groups (Figures 1 and 2). In lulos, most accessions formed a group at the first axes, although accession $05 \mathrm{~T} 1688028$ was far from the centroid of the three axes. Accession 06L082 was found far from the centroid of the first and third axis. Finally, accessions 06L098 and 06L085 were different from the other accessions at the third axis (Figure 1). In tree tomatoes, accession 06TA042 was far from the centroid of the three axes. Accessions 06TA024 and 06TA031 were far from the centroid of the first and second axis, whereas 06TA041, 06TA045 06TA004 and 06TA047 were far from the centroid of the second axis. Finally, accessions 06TA001 and 06TA035 were found to be to the right of the center of the first axis (Figure 2).

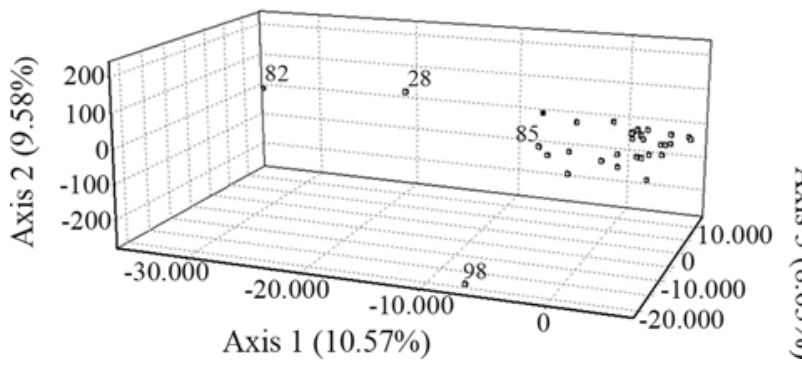

Figure 1 - PCA analysis for lulos. Only accessions differing from the main constellation are represented by their last two numbers.

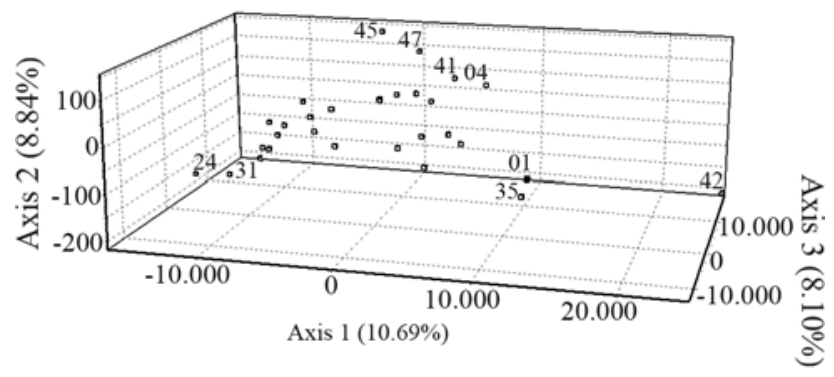

Figure 2 - PCA analysis for tree tomatoes. Only accessions differing from the main constellation are represented by their last two numbers.
To estimate genetic distances, we used the Cavalli-Sforza distance measure (Cavalli-Sforza and Edwards, 1967). The consensus UPGMA tree per species, derived from genetic distances (Tables $S 2$ and $S 3$ ), displayed clusters with low to high statistical support, with bootstrapping values ranging from $0.02 \%-100 \%$ for lulos and $0.004 \%$ $100 \%$ for tree tomatoes. In both cases, accessions 05T1688028 for lulo and 06TA042 for tree tomatoes were chosen as outgroups, with $100 \%$ bootstrapping values clustering out of the other accessions (Figures $S 1$ and S2). In lulos, distances were the highest and clusters independent in accessions 06L082, 06L098 and 06L085, although bootstrapping values were low (17\%-33\%, Figure $S 1)$. In tree tomatoes, high distances and independent clusters with low bootstrapping support prevailed in accessions 06TA031, 06TA24, 06TA045 and 06TA41 (0.6\%-35\%, Figure $S 2)$. These results are consistent with PCA output. Moreover, the low bootstrapping values observed might be related to high genetic differentiation possibly arising from high homozygosity within accessions and the low number of mutually shared alleles, propitious for the formation of several cluster possibilities, each with low statistical support.

S. hirtum 05T1688028 (a wild relative to $S$. quitoense) and S. corymbiflora 06TA042 (a wild relative to S. betaceum) were chosen as outgroups, since PCA output showed these accessions to be consistently and tri-dimensionally separate from the others. This is due to their both coming from different countries as compared to the majority of the accessions tested (05T1688028 was from Venezuela and 06TA042 from Brazil) (Table 1). This separation is also consistent with the two species being distantly related to S. quitoense and S. betaceum (Heiser, 1972; Bohs, 1994). S. corymbiflora is widespread in humid forests of southeastern Brazil and the adjacent Argentina, and is not interfertile with $S$. betaceum (Bohs, 1994). S. hirtum grows throughout the tropics and is found near to related species as S. quitoense (Heiser, 1972). S. hirtum and S. corymbilora were under-represented in the tested sample, with only two accessions in the former and one in the latter (Table 1).

The fact that the other $S$. hirtum accession from Santander, Colombia (06L063) grouped distantly from $S$. hirtum from Venezuela (05T1688028) might be consistent with their different geographic origins. Nevertheless, $S$. hirtum 06L063 did group together with other S. quitoense accessions, thus possibly indicating allelic homoplasy (the close relationship between species), which may have occurred through the same-sized alleles on agarose not necessarily being homologs, consequently with different and recent common ancestors. Thus, differences in sequence, if any, could be masked as the alleles were of the same size. The same principle might also apply to the close relationships between $S$. betaceum, S. hartwegii var racemosa, and $S$. diversifolia, species which grouped together. We also observed a lack of clustering associated with geographic origin in Colombian regions, as well as any other attribute. 
This might reflect the lack of specific sampling for different geographic and distribution regions. Similar results were obtained by Lobo et al. (2007) in a morphological characterization study which included material from the current research.

The pronounced variability observed among lulo accessions is in agreement with previous studies based on morphologic and agronomic traits, thereby indicating the high variation among accessions, most of which represented Colombian entries (Lobo et al., 2007), although this is not the case in $S$. quitoense, where genetic variation is low, based on the morphology of entries from Ecuador (Whalen et al., 1981). This contradiction has been explained by M. Lobo (unpublished results) and Lobo et al. (2007), who proposed that Colombia is the possible center of origin of lulo when based on genetic and linguistic premises, i.e. most Colombian entries present nondomesticated traits such as the presence of spines, and the name "lulo", as used in Colombia, is of Quechua (indigenous) origin, whereas the name "naranjilla", used in Ecuador, is of Spanish origin. Furthermore, these authors, as well as Heiser (1969), mentioned a possible founder effect associated with human dispersion from a common center, namely $\mathrm{Co}-$ lombia.

\section{Implications of diversity, conservation, and breeding}

Because of their codominant, bi (SNPs -in the case of diploid species) or multi-allelic (InDels) nature, we may infer that COSIIs are adequate for diversity analysis. Due to the novel nature of using COSIIs based on the size of PCR products for diversity, we resorted to a small marker sample, which might thus bias analysis. Consequently, care should be taken in interpretation, with confirmation by means of a larger sample of polymorphic markers. Notwithstanding, this study represents an important guiding line for future research.

COSII markers are being used for studies on diversity based on sequence data in tomatoes (Nakitandwe et al., 2007; Van Deynze et al., 2007). COSII sequence data have been instrumental in arriving at a clear differentiation of population level distribution of genetic variation. Thus, most genetic variation among samples was observed in primary centers of diversity and the least in secondary. Moreover, when compared to other SNP and InDel markers, both non-coding arbitrary and EST-based, COSIIs furnished similar estimates of polymorphism (Labate et al., 2009). Future studies on diversity in lulos and tree tomatoes should include comparisons with COSIIs based on sequence data or other co-dominant markers such as SSRs.

Based on the high genetic differentiation among lulo and tree tomato accessions, we might venture upon some inferences. Firstly, Colombia could be the primary center of diversity as has already been suggested (Heiser, 1969; Heiser and Anderson, 1999; Lobo et al., 2007). This hypothesis should be tested by surveying samples of compa- rable sizes from outside this region. In the second place, there was usually no mutual difference among individuals within accessions, thereby implying that collection-sampling should be more directed to several populations, to so sample genetic variation to a greater extent. Larger populations and loci sampling should be considered in future studies to confirm the very high population structure observed in this study. Third, success in obtaining hybrid vigor is highly probable by crossing different accessions and species, providing they are genetically distant, whence, high pathogen resistance and yield-heterosis has been observed in various crosses between $S$. hirtum and $S$. quitoense (Heiser, 1972; Bernal et al., 1998), as well as between $S$. betaceum and S. unilobum accessions (Lobo et al., 2000). Finally, there should be a high probability of success for gene-map construction and QTL analysis among accessions. Hence, we have observed high levels of COSII polymorphism distributed among the 12 tomato chromosomes in different lulo and tree tomato parental combinations (Pratt et al., 2008).

Finally, we illustrate the potential of the SOL genomics initiative, wherefore the use of COSII markers is just one example of the transferability of genomics tools to less developed Solanaceae species such as lulos and tree tomatoes for their future conservation and breeding.

\section{Acknowledgments}

This work was supported by the Colombian Institute for the Development of Science and Technology "Francisco José de Caldas"- COLCIENCIAS. The authors wish to thank Drs. Steven D. Tanksley and Feinan Wu for providing information on COSII markers, and Yaneth Camargo for technical assistance. The authors also wish to express their gratitude to Dr. Leonardo Mariño for critically reviewing the manuscript.

\section{References}

Belkhir K, Borsa P, Chikhi L, Raufaste N and Bonhomme F (2004) GENETIX 4.05, logiciel sous Windows TM pour la génétique des populations. Laboratoire Génome, Populations, Interactions, CNRS UMR 5000, Université de Montpellier II, Montpellier.

Benitez A, Valencia J, Estrada EI and Baena D (1991) Phenotypic characterization of certain accessions in the lulo (Solanum quitoense) germplasm bank. In: Hawkes J, Lester RN, Nee M and Estrada N (eds) Solanaceae III: Taxonomy, Chemistry, Evolution. Royal Botanic Gardens, Kew, pp 437-450.

Bernal J, Lobo M and Londoño M (1998) Documento de Presentación del Material "Lulo La Selva". Corpoica, Rionegro, Antioquia, $77 \mathrm{pp}$.

Bohs L (1991) Crossing studies in Cyphomandra (Solanaceae) and their systematic and evolutionary significance. Am J Bot 78:1683-1693.

Bohs L (1994) Cyphomandra (Solanaceae) Monograph 63. New York Botanical Garden, New York, 175 pp. 
Bohs L (2004) A chloroplast ADN phylogeny of Solanum section Lasiocarpa. Syst Bot 29:177-187.

Bornet B, Goraguer F, Joly G and Branchard M (2002) Genetic diversity in European and Argentinian cultivated potatoes (Solanum tuberosum subsp. tuberosum) detected by intersimple sequence repeats (ISSRs). Genome 45:481-484.

Cavalli-Sforza LL and Edwards AW (1967) Phylogenetic analysis. Models and estimation procedures. Am J Hum Genet 19:233-257.

Felsenstein J (1989) PHYLIP: Phylogeny inference package v. 3.2. Cladistics 5:164-166.

Fulton T, Chunwongse J and Tanksley SD (1995) Microprep protocol for extraction of DNA from tomato and other herbaceous plants. Plant Mol Biol Rep 13:207-209.

Fulton TM, Van der Hoeven R, Eannetta NT and Tanksley SD (2002) Identification, analysis, and utilization of conserved ortholog set markers for comparative genomics in higher plants. Plant Cell 14:1457-1467.

Ghislain M, Spooner DM, Rodriguez F, Villamón F, Nunez J, Vásquez C, Waugh R and Bonierbale M (2004) Selection of highly informative and user-friendly microsatellites (SSRs) for genotyping of cultivated potato. Theor Appl Genet 108:881-890.

Hartl DL (1987) A Primer of Population Genetics. 2nd edition. Sinauer Associates, Sunderland, 303 pp.

He C, Poysa V and Yu K (2003) Development and characterization of simple sequence repeat (SSR) markers and their use in determining relationships among Lycopersicon esculentum cultivars. Theor Appl Genet 106:363-373.

Heiser CB (1969) Nightshades: The Paradoxical Plants. W.H. Freeman \& Company, San Francisco, 301 pp.

Heiser CB (1972) The relationship of the naranjilla $S$. quitoense. Biotropica 4:77-84.

Heiser CB and Anderson G (1999) "New" Solanums. In: Janick J (ed). Perspectives on New Crops and New Uses. ASHS Press, Alexandria V, pp 379-384.

Labate JA, Robertson LD, Wu F, Tanksley SD and Baldo AM (2009) EST, COSII, and arbitrary gene markers give similar estimates of nucleotide diversity in cultivated tomato (Solanum lycopersicum L.). Theor Appl Genet 118:10051014.

Lobo M, Medina CI and Cardona M (2000) Resistencia de campo a la antracnosis de los frutos (Colletotrichum gloeosporioides) en tomate de árbol (Cyphomandra betacea (Solanum betaceum) Cav. Sendt.). Rev Fac Nal Agr Medellin 53:1129-1141.

Lobo M, Medina CI, Delgado O and Bermeo A (2007) Morphological variability of the Colombian collection of lulo (Solanum quitoense Lam.) related Lasiocarpa section species. Rev Fac Nal Agr Medellin 60:3939-3964.

Moncada P and McCouch S (2004) Simple sequence repeat diversity in diploid and tetraploid Coffea species. Genome 47:501-509.

Mueller LA, Solow TH, Taylor N, Skwarecki B, Buels R, Binns J, Lin C, Wright MH, Ahrens R, Wang Y et al. (2005) The
SOL genomics network: A comparative resource for Solanaceae biology and beyond. Plant Physiol 138:13101317.

Nakitandwe J, Trognitz F and Trognitz B (2007) Reliable allele detection using SNP-based PCR primers containing Locked Nucleic Acid: Application in genetic mapping. Plant Methods 3:2.

Pratt RC, Francis DA and Barrero LS (2008) Genomics of tropical solanaceous species: Established and emerging crops. In: Moore PH and Ming R (eds) Genomics of Tropical Crop Plants. Vol 1. Springer, New York, pp 453-467.

Van Deynze A, Stoffel K, Buell CR, Kozik A, Liu J, van der Knaap E and Francis D (2007) Diversity in conserved genes in tomato. BMC Genom 8:465.

Varshney RK, Graner A and Sorrells ME (2005) Genic microsatellite markers in plants: Features and applications. Trends Biotechnol 23:48-55.

Whalen MD, Costich DE and Heiser CB (1981) Taxonomy of Solanum section Lasiocarpa. Gentes Herb 12:41-129.

Wu F, Mueller LA, Crouzillat D, Petiard V and Tanksley SD (2006) Combining bioinformatics and phylogenetics to identify large sets of single-copy orthologous genes (COSII) for comparative, evolutionary and systematic studies: A test case in the euasterid plant clade. Genetics 174:1407-1420.

Wright S (1965) The interpretation of population structure by F-statistics with special regard to systems of mating. Evolution 19:395-420.

\section{Internet Resources}

Agronet website: http://www.agronet.gov.co/www/docs_agronet/200511216 123 caracterizacion frutales.pdf/ (July 6, 2009).

\section{Supplementary Material}

The following online material is available for this article:

Figure S1. Consensus tree using bootstrapping of 10,000 replicates for lulo.

Figure S2. Consensus tree using bootstrapping of 10,000 replicates for tree tomato.

Table S1. COSII Markers selected for screening

Table S2. Genetic distances for lulo and relatives

Table S3. Genetic distances for tree tomato and relatives

This material is available as part of the online article from http://www.scielo.br/gmb

\section{Associate Editor: Everaldo Gonçalves de Barros}

License information: This is an open-access article distributed under the terms of the Creative Commons Attribution License, which permits unrestricted use, distribution, and reproduction in any medium, provided the original work is properly cited. 


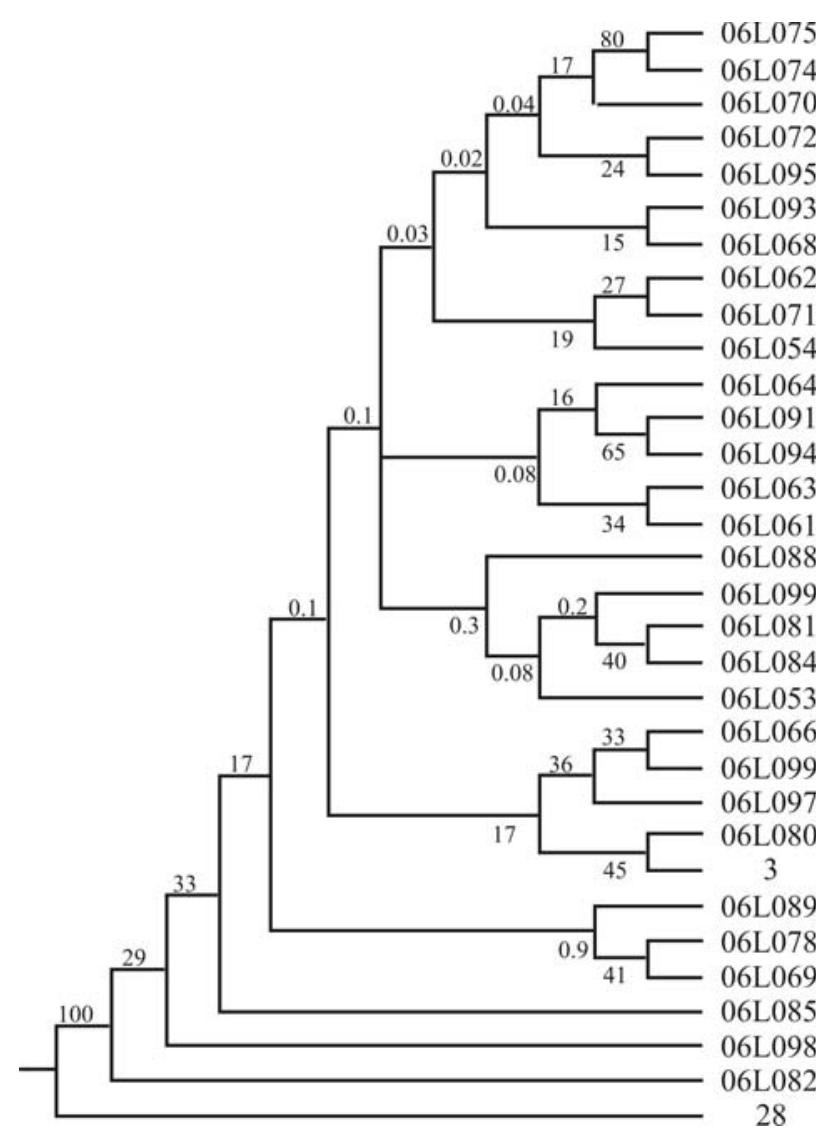

Figure S1 - Consensus tree using bootstrapping of 10,000 replicates for lulo.

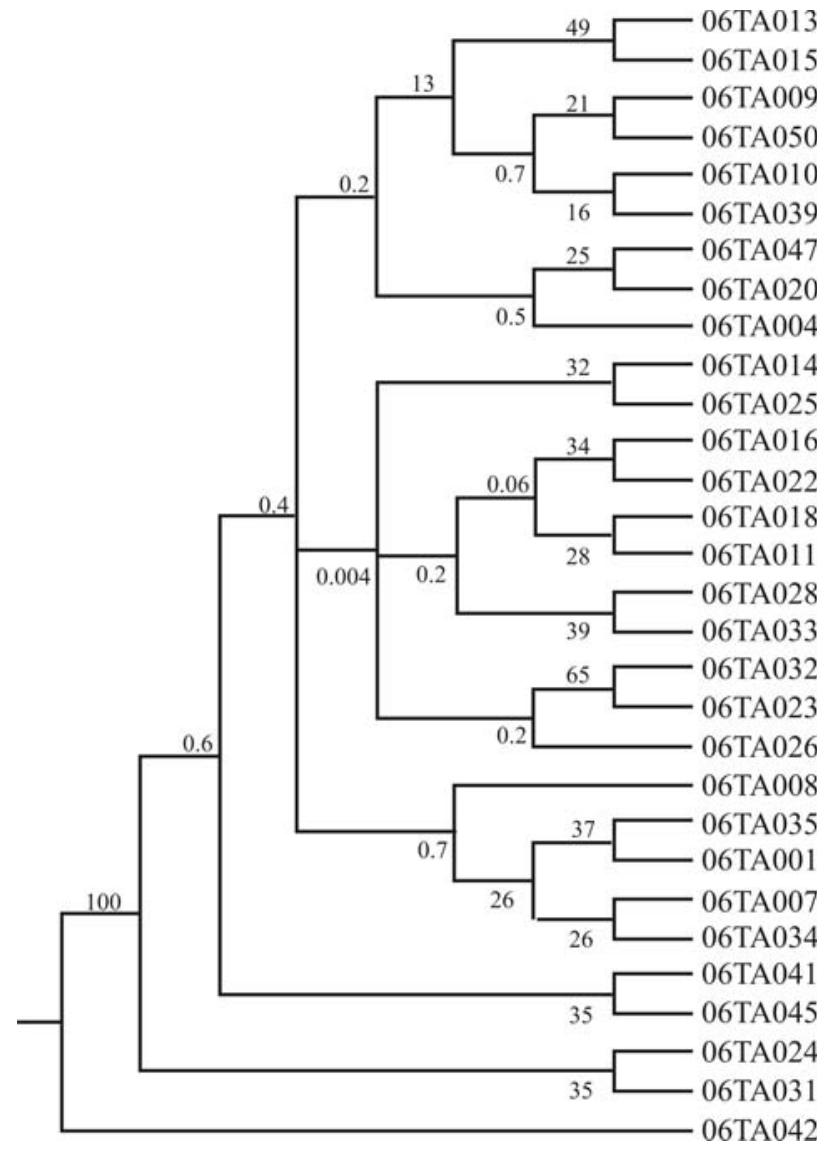

Figure S2 - Consensus tree using bootstrapping of 10,000 replicates for tree tomato. 
Table S1 - COSII Markers selected for screening of lulo and tree tomato entries in the current study. Functional annotation of underlying genes is to be found in http://arabidopsis.org/ or www.sgn.cornell.edu.

\begin{tabular}{|c|c|}
\hline Lulo & Tree tomato \\
\hline C2_At1g02140 & C2_At1g10240 \\
\hline C2_At1g16210 & C2_At1g16210 \\
\hline C2_At1g50575 & C2_At1g26520 \\
\hline C2_At1g56345 & C2_At1g44760 \\
\hline C2_At2g04700 & C2_At1g50575 \\
\hline C2_At2g06530 & C2_At1g71810 \\
\hline C2_At2g18030 & C2_At2g06530 \\
\hline C2_At2g18710 & C2_At2g34470 \\
\hline C2_At2g20860 & C2_At2g34860 \\
\hline C2_At2g34470 & C2_At2g39690 \\
\hline C2_At2g34860 & C2_At2g43360 \\
\hline C2_At2g39690 & C2_At3g04870 \\
\hline C2_At2g43360 & C2_At3g10020 \\
\hline C2_At3g01160 & C2_At3g10220 \\
\hline C2_At3g04710 & C2_At3g11210 \\
\hline C2_At3g06580 & C2_At3g15430 \\
\hline C2_At3g09920 & C2_At3g16150 \\
\hline C2_At3g10020 & C2_At3g17000 \\
\hline C2_At3g10220 & C2_At3g17040 \\
\hline C2_At3g11210 & C2_At3g19630 \\
\hline C2_At3g12490 & C2_At3g21610 \\
\hline C2_At3g16150 & C2_At3g28050 \\
\hline C2_At3g17040 & C2_At3g28720 \\
\hline C2_At3g19630 & C2_At3g52120 \\
\hline C2_At3g21610 & C2_At3g58470 \\
\hline C2_At3g25590 & C2_At3g61140 \\
\hline C2_At3g28720 & C2_At3g62940 \\
\hline C2_At3g46780 & C2_At4g00090 \\
\hline C2_At3g52120 & C2_At4g03210 \\
\hline C2_At3g58470 & C2_At4g12230 \\
\hline C2_At3g61140 & C2_At4g14110 \\
\hline C2_At3g62940 & C2_At4g22200 \\
\hline C2_At4g03210 & C2_At4g24830 \\
\hline C2_At4g22200 & C2_At4g32930 \\
\hline C2_At4g24830 & C2_At4g35930 \\
\hline C2_At4g34700 & $\mathrm{C} 2 \_\mathrm{At} 4 \mathrm{~g} 37130$ \\
\hline C2_At4g37130 & C2_At4g37280 \\
\hline C2_At4g37280 & C2_At5g20180 \\
\hline C2_At4g38810 & C2_At5g23880 \\
\hline C2_At5g06430 & C2_At5g62390 \\
\hline C2_At5g20180 & C2_At5g66530 \\
\hline \multicolumn{2}{|l|}{ C2_At5g23880 } \\
\hline \multicolumn{2}{|l|}{ C2_At5g46630 } \\
\hline \multicolumn{2}{|l|}{ C2_At5g62390 } \\
\hline \multicolumn{2}{|l|}{ C2_At5g62440 } \\
\hline C2_At5g66530 & \\
\hline
\end{tabular}


Table S2 - Genetic distance estimates for lulos and wild relatives used to construct the UPGMA tree in Figure S1.



*Accessions. All accessions are represented by their last two numbers. 
Table S3 - Genetic distance estimates for tree tomatoes and wild relatives used to construct the UPGMA tree in Figure S2.

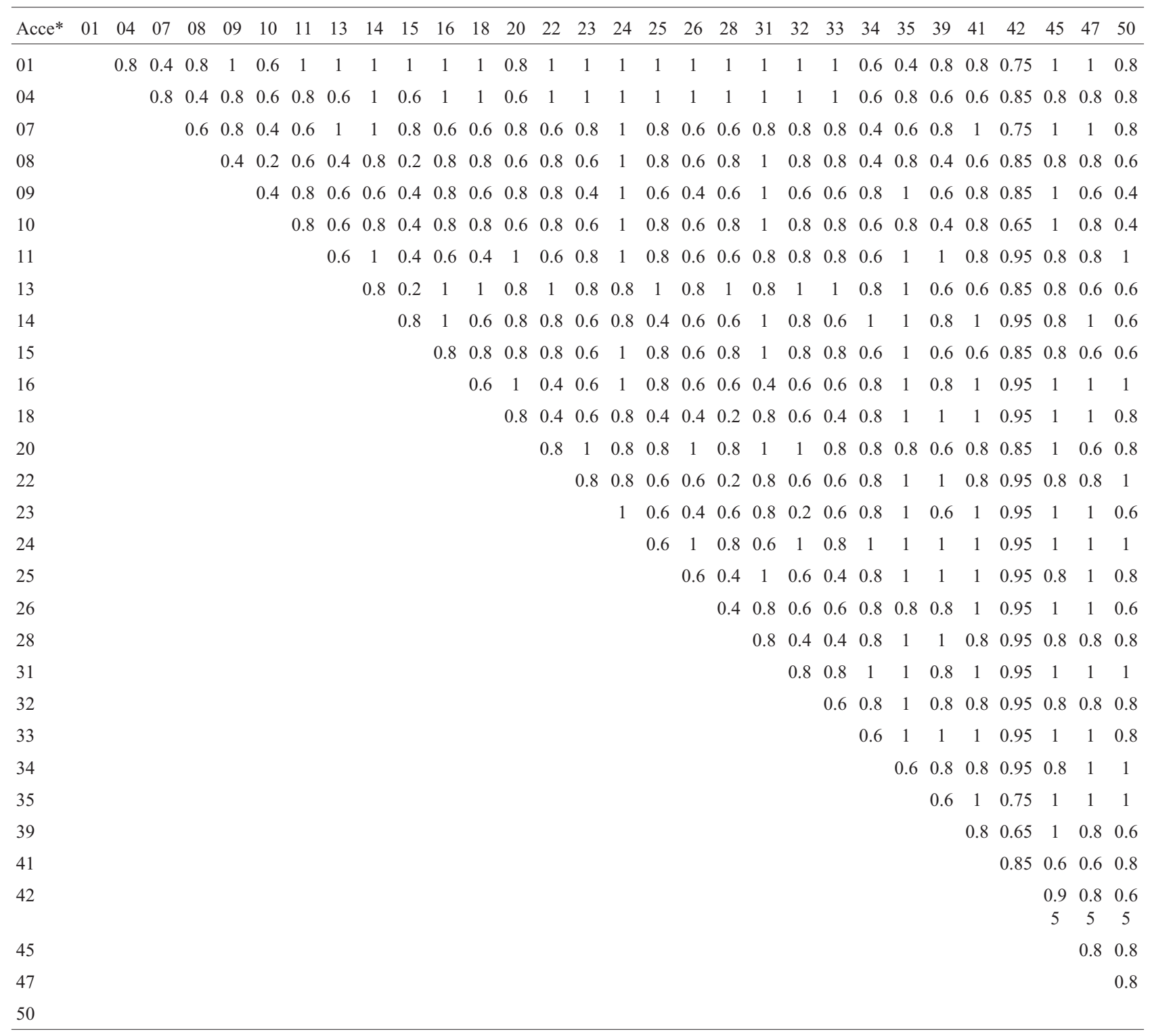

*Accessions. All accessions are represented by their last two numbers. 